Correspondence: SP Shah,

International Centre for Eye Health,

London School of Hygiene

and Tropical Medicine,

Keppel Street,

WC1E 7HT,

London, UK

Tel: + 44207958 8374;

Fax: + 442079588325 .

E-mail: shaheen.shah@|shtm.ac.uk

Eye (2007) 21, 126-127. doi:10.1038/sj.eye.6702439;

published online 26 May 2006

Sir,

\section{Reply to Shah et al}

We thank Drs Shah et al for their interest in our paper on obstructive sleep apnoea (OSA) and optic neuropathy. ${ }^{1}$

Here, we attempt to elaborate on a few points mentioned by their letter to the editor.

In our study, we analysed each eye independently because normal tension glaucoma and various forms of optic neuropathies like nonarteritic ischaemic optic neuropathy, which may be related to OSA, often present unilaterally and asymmetrically, especially in the early stage. $^{2-4}$ Anyway, as suggested by Dr Shah et al, we reanalysed the data by collapsing the data into individuals and analysed using Wilcoxon's test (a nonparametric test). The differences of visual field indexes between OSA and control arms were still found to be statistically significant $(P=0.021$ for the difference between mean deviation in the two arms, and $P=0.001$ for the difference between pattern standard deviation in the two arms, respectively).

Different statistical tools help researchers to analyse data in different aspects and present them at different angles. Shah et al suggested that we should present the difference of visual function indices in means with confidence interval (CI). However, in our series, only a small proportion of OSA patients developed optic neuropathies. Comparing their mean may not yield conclusive information. Therefore, as an alternative, we chose to present the visual field index in a graphical method showing the distribution of data, which gave a clear overall picture demonstrating that a small peak of suboptimal visual field indices was found in the OSA group. Concerning the values of $\mathrm{CI}$, we did present the data in the footnotes of all tables and figures. ${ }^{1}$

Finally, we would like to thank Dr Shah et al for mentioning the importance of study design methodology and terminology. We share their view that these are important aspects in any research.

\section{References}

1 Tsang CSL, Chong SL, Ho CK, Li MF. Moderate to severe obstructive sleep apnoea patients are associated with higher incidence of visual field defect. Eye 2006; 20(1): 38-42.

2 Behbehani R, Mathews MK, Sergott RC, Savino PJ. Nonarteritic anterior ischemic optic neuropathy in patients with sleep apnea while being treated with continuous positive airway pressure. Am J Ophthalmol 2005; 139(3): 518-521.

3 Poinoosawmy D, Fontana L, Wu JX, Bunce CV, Hitchings RA. Frequency of asymmetric visual field defects in normaltension and high-tension glaucoma. Ophthalmology 1998; 105(6): 988-991.

4 Kitizawa Y. Unilateral normal-tension glaucoma. J Glaucoma 1997; 6(1): 50-55.

\section{Tsang}

Department of Ophthalmology, Tuen Mun Hospital, Ching Chung Koon Rd, Tuen Mun, Hong Kong, Hong Kong

Correspondence: C Tsang,

Tel: + 852 24685111;

Fax: +85224420023

E-mail: colette_tsg@hotmail.com

Eye (2007) 21, 127. doi:10.1038/sj.eye.6702440; published online 26 May 2006

Sir,

Reversible structural disruption of the outer retina in acute welding maculopathy

Exposure to welding arcs might result in maculopathy if appropriate protective eyewear is not used. The damage is thought to stem from photochemical injury to the photoreceptors. ${ }^{1,2}$ We report the correlation of clinical and optical coherence tomography (OCT) findings in a case of acute welding maculopathy.

\section{Case report}

A 19-year-old male presented with blurred vision in his right eye after staring at a welder earlier that day. The patient was aphakic in both eyes after lensectomy at the age of 10 years for subluxated microspherophakic lenses. Corrected visual acuity 3 months before presenting to our clinic was $6 / 7.5$ in the right eye. Visual acuity in the left eye was light perception as a result of recurrent rhegmatogenous retinal detachment after trauma and 